\section{Association between the polymorphisms of the selected genes encoding dopaminergic system with ADHD and autism}

Attention-deficit hyperactivity disorder (ADHD) and autism are heritable, polygenic neurodevelopmental disorders with similar symptoms, onset in childhood, and more frequent occurrence in boys than in girls (Muhle et al., 2004; Wallis, 2010).

The study evaluated the association of ADHD and/or autism with dopamine receptor D4 exon 3 variable number of tandem repeats (DRD4 VNTR) polymorphism, catechol-o-methyltransferase (COMT Val108/158Met; rs4680), dopamine-beta-hydroxylase (DBH -1021C/T; rs1611115) and monoamine oxidase type B (MAO-B intron 13; rs1799836) polymorphisms in ethnically homogenous non-related Caucasian male subjects of European (Croatian) ancestry: 102 medication-free children $(9.2 \pm 2.5$ years old) who met DSM-IV criteria for ADHD, 80 subjects (18.2 \pm 10.3 years old) who met DSM-IV criteria for autism, and had $43.2 \pm 8.9$ Childhood Autism Rating Scale scores, and 128 healthy control subjects (16.9 \pm 9.0 years old). Genotyping of DRD4 VNTR was done using polymerase chain reaction and $2 \%$ agarose gel electrophoresis, and individuals were categorized into DRD4 long (L) allele carriers (possessing at least one copy of 7 or more repeats allele) and short (SS) homozygotes (possessing 2 copies of 2-6 repeats allele).
Genotyping of rs4680, rs1611115 and rs1799836 was done using a Taqman-based allele-specific polymerase chain reaction assays (Applied Biosystems, Foster City, CA). Subjects were categorized into COMT Met/Met homozygous genotype vs. Val carriers, DBH CC genotype vs. T carriers, and MAO-B A or G carriers. Results (Table 1) were evaluated with two tailed $\chi^{2}$ test, standardized residuals $(R \geq 2.00)$, odds ratio (OR), 95\% CI, $z$ and Cramer's $C$ or $V$ statistics. $P \leq 0.0125$ was considered significant after Bonferroni correction for multiple comparisons.

Genotype frequencies in DRD4 VNTR in autism and healthy controls, and in the DBH $-1021 \mathrm{C} / \mathrm{T}$ in ADHD $(P<0.05)$ deviated from Hardy-Weinberg equilibrium (HWE), while other genotype frequencies were in the expected HWE $(P>0.05)$. DRD4 L allele carriers in ADHD and autistic groups and COMT Met/Met genotype in healthy subjects contributed to the significant $\chi^{2}$ statistics. There were less DRD4 L allele carriers than SS genotype carriers in autistic subjects compared to ADHD $(z=3.324 ; P=0.001$; $O R=2.4 ; 95 \% C I=1.022-5.548)$ or control groups, confirming the role of $\mathrm{L}$ allele in attention, and supporting the hypothesis (Grady et al., 2005) that L allele has a major role in the etiology of ADHD, but not in autism. More COMT Met/Met homozygotes than Val carriers were found in groups with $\operatorname{ADHD}(z=2.946 ; P=0.003$; $O R=3.75 ; 95 \% C I=1.951-7.200)$ or autism $(z=2.536 ; P=0.011$; $O R=4.05 ; 95 \% C I=2.024-8.124)$ than in control group, suggesting

Table 1

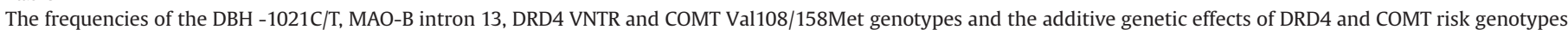
in healthy control subjects and in subjects with ADHD or autism.

\begin{tabular}{|c|c|c|c|}
\hline & $\begin{array}{l}\text { Healthy subjects } \\
N(\%)\end{array}$ & $\begin{array}{l}\text { Subjects with ADHD } \\
N(\%)\end{array}$ & $\begin{array}{l}\text { Subjects with autism } \\
N(\%)\end{array}$ \\
\hline \multicolumn{4}{|c|}{ DRD4 genotype } \\
\hline SS & $92(71.9)$ & $60(58.8)$ & $48(85.7)$ \\
\hline L carriers & $36(28.1)$ & $42(41.2)$ & $8(14.3)$ \\
\hline \multicolumn{4}{|c|}{$\begin{array}{l}\chi^{2}=12.849 ; \text { d.f. }=2 ; P=0.002 ; \text { power }=0.789 ; \Phi c=0.21 ; R=2.05 \text { for } \mathrm{L} \text { carriers in ADHD; } R=2.15 \text { for } \mathrm{L} \text { carriers in autism } \\
\text { COMT genotype }\end{array}$} \\
\hline Met/Met & $18(14.1)$ & $31(30.4)$ & $23(28.8)$ \\
\hline Val carriers & $110(85.9)$ & $71(69.6)$ & $57(71.2)$ \\
\hline \multicolumn{4}{|c|}{$\begin{array}{l}\chi^{2}=10.334 ; \text { d.f. }=2 ; P=0.006 ; \text { power }=0.662 ; \Phi c=0.18 ; R=2.15 \text { for Met/Met homozygotes in healthy subjects } \\
\text { DBH genotype }\end{array}$} \\
\hline $\mathrm{CC}$ & $79(61.7)$ & 55 (53.9) & $49(61.2)$ \\
\hline $\mathrm{T}$ carriers & $49(38.3)$ & $47(46.1)$ & $31(38.8)$ \\
\hline \multicolumn{4}{|c|}{$\begin{array}{l}\chi^{2}=31.646 ; \text { d.f. }=2 ; P=0.439 ; \text { power }=0.077 \\
\text { MAO-B genotype }\end{array}$} \\
\hline G & $54(42.2)$ & $41(40.2)$ & $34(43.0)$ \\
\hline A & $74(57.8)$ & $61(59.8)$ & $45(57.0)$ \\
\hline \multicolumn{4}{|c|}{$\begin{array}{l}\chi^{2}=0.165 ; \text { d.f. }=2 ; P=0.921 ; \text { power }=0.212 \\
\text { Additive genetic effects of DRD4 and COMT risk }\end{array}$} \\
\hline 0 & $74(57.8)$ & $42(41.2)$ & $34(60.7)$ \\
\hline 1 & $51(39.8)$ & $47(46.1)$ & 19 (33.9) \\
\hline 2 & $3(2.4)$ & $13(12.7)$ & $3(5.4)$ \\
\hline \multicolumn{4}{|c|}{$\chi^{2}=14.689 ;$ d.f. $=4 ; P=0.005 ;$ power $=0.750 ; \Phi c=0.23 ; R=2.39$ in ADHD carriers of both risk genotypes } \\
\hline
\end{tabular}

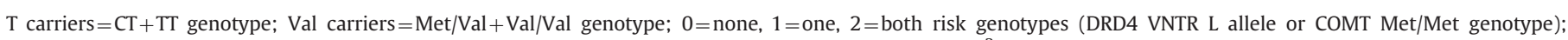

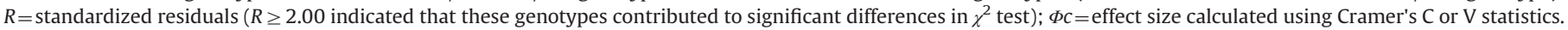
Due to Bonferroni correction, $P \leq 0.0125$ was considered significant. 
that subjects with ADHD and autism have deficits in prefrontal circuits that modulate cognitive functions (Bellgrove et al., 2005). When subjects were categorized according to none, one or both risk genotypes (DRD4 VNTR L allele or COMT Met/Met genotype) the additive effect of the two risk genotypes was detected in subjects with ADHD.

Our results confirmed that DRD4 VNTR and COMT Val108/ $158 \mathrm{Met}$, in contrast to DBH $-1021 \mathrm{C} / \mathrm{T}$ or MAO-B intron 13 polymorphisms, are associated with ADHD and autism in smaller ethnically homogenous groups of non-related male Caucasians, contributing to hypothesis that both disorders have shared heritability and common biological/genetic factors (Rommelse et al., 2010).

\section{Acknowledgments}

The study was supported by the Croatian Ministry of Science, Education and Sport, Grant nos. 098-0982522-2455; 098-09825222457; 119-1081870-2396; and 098-1081870-2395.

\section{References}

Bellgrove, M.A., Domschke, K., Hawi, Z., Kirley, A., Mullins, C., Robertson, I.H., Gill, M., 2005. The methionine allele of the COMT polymorphism impairs prefrontal cognition in children and adolescents with ADHD. Exp. Brain Res. $163,352-360$

Grady, D.L., Harxhi, A., Smith, M., Flodman, P., Spence, M.A., Swanson, J.M., Moyzis, R.K., 2005. Sequence variants of the DRD4 gene in autism: further evidence that rare DRD4 7R haplotypes are ADHD specific. Am. J. Med. Genet. Part B: Neuropsychiatric Genet. 136B, 33-35.
Muhle, R., Trentacoste, S.V., Rapin, I., 2004. The genetics of autism. Pediatrics 113 e472-486.

Rommelse, N.N., Franke, B., Geurts, H.M., Hartman, C.A., Buitelaar, J.K., 2010. Shared heritability of attention-deficit/hyperactivity disorder and autism spectrum disorder. Eur. Child Adolesc. Psychiatry 19, 281-295.

Wallis, D., 2010. The search for biomarkers for attention deficit/hyperactivity disorder. Drug News Perspect. 23, 438-449.

Matea Nikolac Perkovic ${ }^{1}$, Gordana Nedic Erjavec ${ }^{1}$, Jasminka Stefulj, Dorotea Muck-Seler, Nela Pivac* Rudjer Boskovic Institute, Zagreb, Croatia E-mail address: npivac@irb.hr (N. Pivac)

Dubravka Kocijan Hercigonja Polyclinic Kocijan/Hercigonja, Zagreb, Croatia

Dubravka Hranilovic Faculty of Science, University of Zagreb, Croatia

Mario Curkovic, Katarina Dodig-Curkovic Josip Juraj Strossmayer University of Osijek, Croatia

Received 8 July 2013

\footnotetext{
* Correspondence to: Division of Molecular Medicine, Rudjer Boskovic Institute PO Box 180, HR-10002 Zagreb, Croatia. Tel.: +38514571 207; fax: + 38514561010 .

1 These authors contributed equally to this work.
} 